\title{
Multiple anodic regeneration of exfoliated graphite electrodes spent in the process of phenol electrooxidation
}

\author{
P. Krawczyk • J. M. Skowroński
}

Received: 17 October 2013 /Revised: 12 November 2013 /Accepted: 14 November 2013 /Published online: 11 December 2013

(C) The Author(s) 2013. This article is published with open access at Springerlink.com

\begin{abstract}
The present paper deals with the studies concerning anodic regeneration of exfoliated graphite (EG) electrodes coated with oligomer products of incomplete phenol electrooxidation. The electrochemical activity of regenerated samples depends on the concentration of regenerating electrolyte and potential applied during the regeneration. The effective method of a single-step regeneration of spent EG electrodes was found to be anodic treatment proceeded in $6 \mathrm{M}$ $\mathrm{KOH}$ at the potential of $1.3 \mathrm{~V}$ vs. $\mathrm{Hg} / \mathrm{HgO} / 0.5 \mathrm{M} \mathrm{KOH}$. During the oxidative regeneration of $\mathrm{EG}$, the physical and chemical interactions between intensively generated active oxygen and/or $\mathrm{OH} \cdot$ radical and oligomer covering the EG surface take place. As has been proved by FTIR and XPS analyses, active oxidative agents cause significant modification of chemical composition of oligomer that resulted in enhanced concentration of surface functionalities mainly involving $\mathrm{C}=\mathrm{O}$ bonds. The results of multiple regeneration of EG electrode, considered as promising method for practical application, showed that the highest efficiency of regeneration is attained due to potentiostatic treatment carried out in $6 \mathrm{M} \mathrm{KOH}$ at the potential of $1.2 \mathrm{~V}$. The electrochemical activity of EG regenerated at this potential increases gradually with the number of regenerating loops and after the third regeneration is almost fourfold higher compared to that of the original EG.
\end{abstract}

Keywords Exfoliated graphite - Phenol electrooxidation . Regeneration treatments $\cdot$ Anodic regeneration

P. Krawczyk • J. M. Skowroński $(\bowtie)$

Institute of Chemistry and Technical Electrochemistry, Poznań University of Technology, ul. Piotrowo 3, 60-965 Poznań, Poland

e-mail: jan.skowronski@put.poznan.pl

\section{Introduction}

Depending on the type of electrolyte as well as electrode material, the process of electrochemical oxidation of phenol may proceed according to different pathways. One of them, based on the formation of polymer structures, is recognized as a pivotal step on the way to complete oxidation of phenol [1-4]. The investigations solving the problem of electrode deactivation by oligomer products of incomplete oxidation of phenol can be divided into two groups. Within the first one, research is focused on finding active electrode materials and favorable conditions of the process enabling the entire oxidation of phenol to $\mathrm{CO}_{2}$ and water with simultaneous minimization of oligomer formation. Among the materials commonly applied to electrooxidation of phenol are metals (e.g., $\mathrm{Pt}, \mathrm{Au}$,) [2, 3, 5] and oxides (e.g., $\mathrm{IrO}_{2}, \mathrm{PbO}_{2}, \mathrm{RuO}_{2}$ ) [6, 7]. A completely different group of electrodes used for phenol electrooxidation are carbon materials, such as diamond [8,9], glass-like carbon [10,11], carbon fibers [11], and exfoliated graphite (EG) [12-15]. The minimization of passivation effect can be reached by the modifications of applied electrolyte as well as by the use of appropriate conditions of electrooxidation. The decrease in electrode activity may be inhibited and even avoided if the initial concentration of phenol is low, and the process is conducted at increased temperature [16,17], with high current density or high potential [2-4].

If the dimerization processes occur with high efficiency, the formation of oligomer compounds dominates which results in deactivation of electrode material. In such a case, the process of electrochemical oxidation cannot be continued with high efficiency. To avoid the costs associated with the necessity of electrode replacement for a new one, the regeneration of spent electrodes should be taken into consideration. The type of regeneration treatment mainly depends on the type of bonds existing between the electrode material and oligomer 
compounds deposited onto its surface. Considerably, a larger number of works are concerned with thermal [18-21], chemical [19-22], and electrochemical [23-25] regeneration of carbons covered by adsorbed phenol or its derivatives. The electrochemical regeneration of spent carbons is realized by indirect mode proceeding in electrolytes containing $\mathrm{NaCl}$ due to electrochemical formation of regenerating agents such as $\mathrm{OH} \cdot$ radical and/or $\mathrm{HClO}$ [23-25]. The process of regeneration becomes much more complicated if intermediate products of phenol electrooxidation are chemically bonded to the carbon surface.

Our previous works concerning the regeneration of EG electrodes covered by oligomer products of phenol electrooxidation showed that both thermal [13] and electrochemical [15] treatments can be considered as an effective way of restoration of EG electrochemical properties. The formation of EG/carbon composite characterized by increased porosity and enhanced concentration of surface functional groups containing oxygen atoms is responsible for a significant improvement of electrochemical activity of thermally regenerated EG [13].

The interactions between active hydrogen violently generated during deep cathodic reduction and oligomer covering the EG surface have recently been shown to have a great significance in reaching high efficiency of EG reactivation [15]. Due to an intensive attack of active hydrogen, the oligomer layer becomes porous; additionally, the significant modification of its chemical composition occurs. The appearance of both factors ensures over a threefold enhancement of electrochemical activity compared to the original EG.

In the present paper, we study the process of anodic regeneration of EG exhausted by oligomer products formed during previous electrochemical oxidation of phenol. The process of EG regeneration was carried out by the potentiostatic method in electrolyte of different $\mathrm{KOH}$ concentrations without any additives. The efficiency of anodic regeneration was examined in a renewed process of phenol electrooxidation realized by cyclic voltammetry technique. The explanation of electrochemical results was supported by the data of chemical composition (X-ray photoelectron spectroscopy (XPS) and Fourier-transform infrared (FTIR) spectroscopy), structural properties (Brunauer-Emmett-Teller (BET) measurements) and morphological features (scanning electron microscopy (SEM) analysis) of the regenerated EG surface.

\section{Experiments}

EG was synthesized by the thermal exfoliation of a stage 4 graphite intercalation compound with sulfuric acid $\left(\mathrm{H}_{2} \mathrm{SO}_{4}\right.$ GIC), formed beforehand using anodic oxidation of flaky graphite (with diameter ranging from 32 to $71 \mu \mathrm{m}$ ) in $18 \mathrm{M}$ $\mathrm{H}_{2} \mathrm{SO}_{4}[26]$.

\section{Electrochemical treatments}

The process of electrochemical oxidation of phenol was performed by cyclic voltammetry (CV) technique in electrolyte solution containing $0.1 \mathrm{M}$ phenol in $0.5 \mathrm{M} \mathrm{KOH}$. A threecompartment cell was composed of powder-type EG electrode as a working electrode, $\mathrm{Hg} / \mathrm{HgO} / 0.5 \mathrm{M} \mathrm{KOH}$ electrode as a reference electrode, and a graphite rod (5 $\mathrm{mm}$ in diameter) playing a role as a counter electrode. Before each measurement, $15 \mathrm{mg}$ of electrode material was inserted into a pocket, made of porous polymer material, around the current collector. The details of electrode preparation procedure were described in our previous papers [12-15]. The processes of voltammetric oxidation of phenol were performed at a scan rate of $0.1 \mathrm{mV} \mathrm{s}^{-1}$ in the potential range from the rest potential of electrode $\left(E_{\mathrm{R}}\right)$ to $0.8 \mathrm{~V}$.

After the entire 3 cycles of phenol oxidation, the process was interrupted, the EG sample coated with oligomer products of phenol oxidation (sample denoted as EG-F) was taken out from the electrolytic cell and placed into another one containing $\mathrm{KOH}$ solution without phenol, in which the anodic regeneration was conducted. Anodic regeneration of exhausted EG was carried out by potentiostatic method in a similar electrolytic cell as in the case of phenol electrooxidation but with the use of $\mathrm{KOH}$ solution free of phenol as a regenerating electrolyte. To investigate the influence of $\mathrm{KOH}$ concentration on the recovery of electrochemical activity of EG, the concentrations of $\mathrm{KOH}$ solution were $0.5,4$, and $6 \mathrm{~mol} \mathrm{dm}^{-3}$. The potentials of anodic treatment of exhausted EG were 1.2 and $1.3 \mathrm{~V}$, whereas the period of time was equal to $2 \mathrm{~h}$. The efficiency of electrochemical activity recovery due to anodic regeneration was examined by comparing the anodic peak charges recorded during the processes of phenol electrooxidation performed before and after regeneration treatment. To prevent the regenerated EG/oligomer from the loss of its acquired activity, instantly after finishing the process of regeneration, the electrode was removed from the electrolytic cell used for regeneration and immersed into a similar cell, filled beforehand with $0.1 \mathrm{M}$ phenol in $0.5 \mathrm{M} \mathrm{KOH}$. Electrochemical conditions of phenol oxidation with regenerated EG were similar to those described elsewhere. Before starting the renewed process of phenol electrooxidation, the regenerated electrode was equilibrated at an opened electrical circuit until the constant value of potential was reached. The information on changes in chemical composition of the EG surface that resulted from electrochemical treatment in phenol-free electrolytes of different concentration of $\mathrm{KOH}\left(0.5,4\right.$, and $\left.6 \mathrm{~mol} \mathrm{dm}^{-3}\right)$ was obtained from the cyclic voltammetry measurements. In this case, the potential range was disposed on $E_{\mathrm{R}} \rightarrow 0.8 \mathrm{~V} \rightarrow$ $-0.95 \mathrm{~V} \rightarrow E_{\mathrm{R}}$ with a scan rate of $0.1 \mathrm{mV} \mathrm{s}^{-1}$.

The last part of the present investigations was focused on checking if or not the multiple electrochemical regeneration of spent EG electrodes is possible. The measurements which 
involved three regeneration loops, each consisting of 3 cycles of phenol oxidation carried out within the potential range $E_{\mathrm{R}}$ $\leftrightarrow 0.8 \mathrm{~V}$ with a scan rate $0.1 \mathrm{mV} \mathrm{s}^{-1}$ followed by anodic treatment of spent electrode material in $6 \mathrm{M} \mathrm{KOH}$ at 1.2 and $1.3 \mathrm{~V}$ for $2 \mathrm{~h}$ were performed. Instantly after finishing the process of regeneration, the electrode was immediately removed from the electrolytic cell and immersed into a cell filled with $0.1 \mathrm{M}$ phenol in $0.5 \mathrm{M} \mathrm{KOH}$. Omitting the washing and drying operations was justified by the risk of partial decomposition of active species generated on the surface of regenerated electrodes leading to the loss of their just created activity.

Physicochemical characterization

The chemical properties of regenerated EG were examined by FTIR and XPS analyses. X-ray photoelectron spectroscopy analysis was performed with Vacuum Systems Workshop (VSW) using a non-monochromatized $\mathrm{Al} \mathrm{K} \alpha$ radiation $(1,486.6 \mathrm{eV})$ operated at $15 \mathrm{kV}$ and $200 \mathrm{~W}$. The obtained XPS spectra were calculated using XPSpeak 41 computer software. The binding energy scale was corrected by referring to the graphitic peak at $284.6 \mathrm{eV}$. FTIR measurements were realized using the BRUKER model $113 \mathrm{~V}$ IR spectrometer by $\mathrm{KBr}$ technique. Prior to each FTIR measurement, the sample of exfoliated graphite was mixed with $\mathrm{KBr}$ followed by grinding in an agate mortar, desorption under vacuum, and compression with the use of hydraulic press. The changes in the BET surface area of the original EG, EG/oligomer composite formed during the process of phenol electrooxidation, and EG/oligomer composite after anodic regeneration were determined from the isotherms obtained by $\mathrm{N}_{2}$ adsorption at $77 \mathrm{~K}$ with ASAP 2010 apparatus and calculated using the BET equation. The changes in morphology of EG that resulted from both the formation of the products of phenol oxidation and the process of anodic regeneration were examined using a scanning electron microscope (Hitachi S-3400 N).

\section{Results and discussion}

\section{Electrochemical oxidation of phenol}

Figure 1 displays cyclic voltammograms recorded during the electrooxidation of $0.1 \mathrm{M}$ phenol at the electrode made of original EG. The well-defined anodic peak seen for the first cycle at the potential of $0.38 \mathrm{~V}$ can be ascribed to the reaction of phenol oxidation [12-14]. As can be seen from this figure, the intensities as well as anodic charges markedly fell for the second and third cycles. The anodic charges for all the investigated electrodes are displayed in Table 1 . The passive, inactive layer of insoluble oligomer products of incomplete phenol oxidation is responsible for the worsening of electrochemical activity of EG after the first cycle. The surface area of the

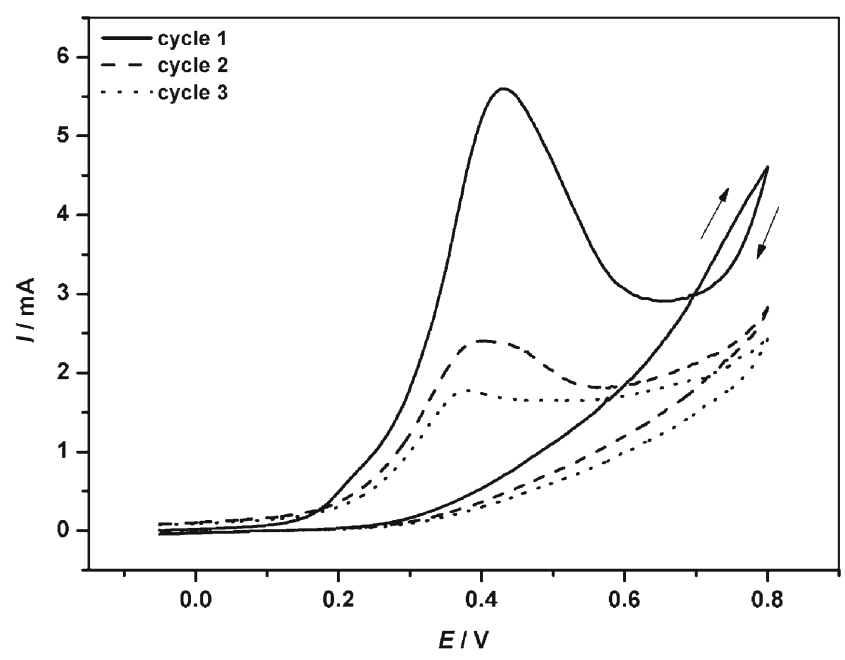

Fig. 1 Voltammetric curves recorded in $0.1 \mathrm{M}$ solution of phenol in $0.5 \mathrm{M} \mathrm{KOH}$ for original EG. Cycle 1 (straight line), cycle 2 (dashed line), and cycle 3 (dotted line). Potential range: $E_{\mathrm{R}} \leftrightarrow 0.8 \mathrm{~V}$ vs. $\mathrm{Hg} / \mathrm{HgO} / 0.5$ $\mathrm{KOH}$

investigated electrode almost entirely covered by oligomeric layer is over fourfold lower compared to the starting EG. After finishing the first cycle of phenol oxidation, the specific surface area decreases to 9.4 from $30.5 \mathrm{~m}^{2} \mathrm{~g}^{-1}$ for the original EG used for oxidation. Because of such features, an access of phenol molecules to the active sites located at the surface of EG electrode is hindered, and in consequence, the inhibition of the phenol electrooxidation reaction in the subsequent cycles takes place. To overcome the problem of very fast loss of the EG electrode activity followed by the necessity of electrode replacement for a new one, further investigations were devoted to searching for an effective method of regeneration of spent EG electrodes.

CVs recorded during oxidation of $0.1 \mathrm{M}$ phenol dissolved in $0.5 \mathrm{M} \mathrm{KOH}$ on electrodes made of regenerated $\mathrm{EG}$, previously coated with oligomer layer during the 3 cycles of voltammetric oxidation of phenol, are shown in Figs. 2, 3, and 4 . The processes of anodic regeneration were conducted by potentiostatic technique for $2 \mathrm{~h}$ at the potential of $1.3 \mathrm{~V}$ in electrolyte containing $0.5 \mathrm{M} \mathrm{KOH}$ (sample EG-F-0.5AR-1.3), $4 \mathrm{M} \mathrm{KOH} \mathrm{(sample} \mathrm{EG-F-4AR-1.3),} \mathrm{and} 6 \mathrm{M} \mathrm{KOH}$ (sample EG-F-6AR-1.3), respectively. Similar to Fig. 1, two characteristic electrochemical features can be observed on CVs shown in Figs. 2, 3, and 4. One of them, at the potential of about $0.41 \mathrm{~V}$, is associated with the appearance of anodic peak corresponding to phenol oxidation, whereas the second one, at the potential of $0.76 \mathrm{~V}$, illustrates the secondary reactions of phenol oxidation and/or oxidation of previously formed products of the regarded reaction. Compared to Fig. 1, anodic charges being an indication of recovered electrochemical activity of regenerated samples considerably increase as a consequence of their interaction with oxygen violently generated during anodic regeneration (Table 1). From the comparison of 
Table 1 Anodic charges calculated for original EG and EG/oligomer after their anodic regeneration

\begin{tabular}{lllllll}
\hline Ample & Figure & Preparation conditions & \multicolumn{2}{c}{ Anodic charge density (As g $\left.{ }^{-1}\right)$} \\
\cline { 4 - 7 } & & & Cycle 1 & Cycle 2 & Cycle 3 & Cycles 1-3 \\
\hline Original EG & 1 & & $1,350.7$ & 770.7 & 648.7 & $2,770.1$ \\
EG-F-0.5AR-1.3 & 2 & EG/oligomer after regeneration at 1.3 V in 0.5 M KOH & $3,360.2$ & $2,181.4$ & $1,740.8$ & $7,282.4$ \\
EG-F-4AR-1.3 & 3 & EG/oligomer after regeneration at 1.3 V in 4 M KOH & $4,828.2$ & $3,776.9$ & $3,321.5$ & $11,926.6$ \\
EG-F-6AR-1.3 & 4 & EG/oligomer after regeneration at 1.3 V in 6 M KOH & $6,747.0$ & $5,578.9$ & $4,885.6$ & $17,211.5$ \\
EG-F-6AR-1.2 & 10 & EG/oligomer after regeneration at 1.2 V in 6 M KOH & $4,826.2$ & $3,509.5$ & $3,094.8$ & $11,430.6$ \\
EG-F-6AR1.3 $\times 3$ & 11 & EG/oligomer after three regeneration loops at 1.3 V in 6 M KOH & $5,063.6$ & $3,610.2$ & $3,102.2$ & $11,775.9$ \\
EG-F-6AR-1.2×3 & 12 & EG/oligomer after three regeneration loops at 1.2 V in 6 M KOH & $5,169.6$ & $4,154.9$ & $3,835.5$ & $13,178.7$ \\
\hline
\end{tabular}

the phenol oxidation peak intensities as well as values of the anodic charges, it is evident that the concentration of $\mathrm{KOH}$ solution used in the regeneration process plays a crucial role in the restoration of electrochemical activity of regenerated samples. As can be seen, the electrochemical activity of regenerated electrodes gradually increases along with the increase in $\mathrm{KOH}$ concentration. Six molars KOH appeared to be the most profitable concentration of electrolyte for anodic regeneration. Anodic charge calculated for the first cycle for sample EG-F6AR-1.3 (Fig. 4) is almost fivefold higher compared to the original EG and simultaneously 100 and $39 \%$ higher than anodic charges noted for EG after its anodic regeneration in 0.5 (EG-F-0.5AR-1.3) and $4 \mathrm{M} \mathrm{KOH} \mathrm{(EG-F-4AR-1.3),} \mathrm{re-}$ spectively (Table 1). Although the disadvantageous tendency of electrochemical activity to diminish after the first oxidation cycle is still observed for regenerated samples, it is remarkable that the activity level exhibited on cycling by these samples is still considerably higher compared to the original EG. Taking into account the peak charges recorded for the second and

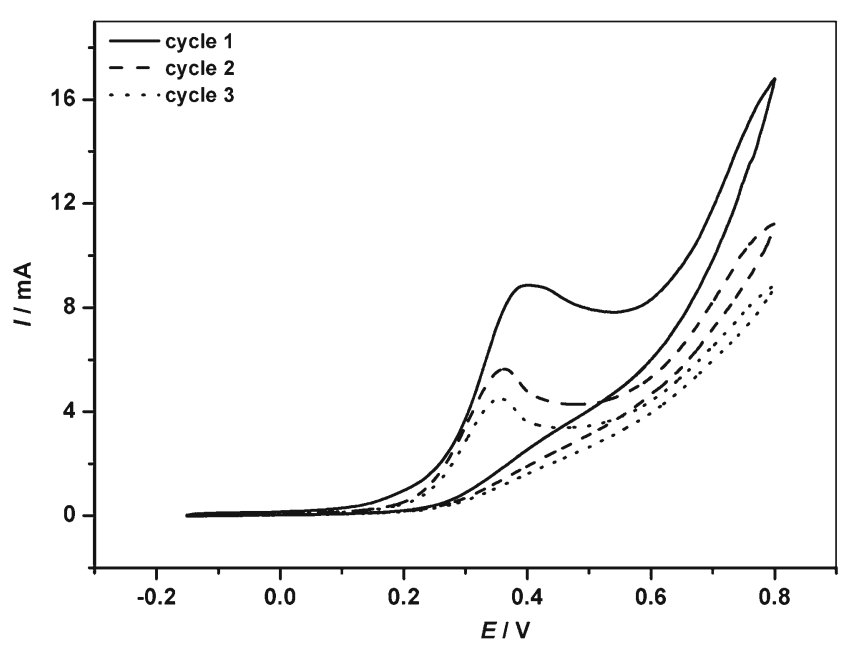

Fig. 2 Voltammetric curves recorded in $0.1 \mathrm{M}$ solution of phenol in $0.5 \mathrm{M} \mathrm{KOH}$ for EG after its anodic regeneration at the potential of $1.3 \mathrm{~V}$ in $0.5 \mathrm{M} \mathrm{KOH}$ (sample EG-F-0.5AR-1.3). Cycle 1 (straight line), cycle 2 (dashed line), and cycle 3 (dotted line). Potential range: $E_{\mathrm{R}} \leftrightarrow 0.8 \mathrm{~V}$ vs. $\mathrm{Hg} / \mathrm{HgO} / 0.5 \mathrm{KOH}$ third cycle, one can observe that the highest electrochemical activity during the second and third cycles of the renewed process of phenol electrooxidation is observed for sample EG that is subjected beforehand to anodic regeneration in $6 \mathrm{M}$ KOH (EG-F-6AR-1.3; Fig. 4, Table 1). Concerning the described electrochemical features, it can be assumed that the intensities and values of peak charges attained for the respective electrodes during the successive oxidation cycles are connected with their electrochemical activity displayed in secondary reactions of phenol oxidation occurring within the potential range of $0.55-0.8 \mathrm{~V}$. The mentioned reactions probably proceeding on the surfaces of EG partially covered by previously formed oligomer products are illustrated by the gradual increase in anodic currents that form current waves with the maximum at around $0.78 \mathrm{~V}$. The intensity of these waves depends on the type of the investigated electrode and reaches the highest level for sample EG-F-6AR-1.3 (Fig. 4). Numerous irregularities seen on CV for this sample within the considered potential range indicate that the secondary

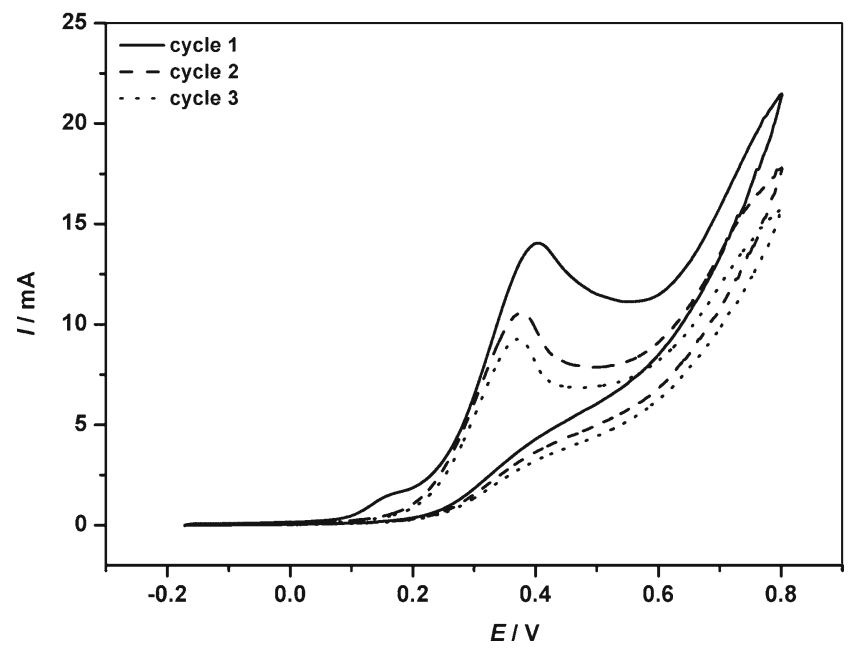

Fig. 3 Voltammetric curves recorded in $0.1 \mathrm{M}$ solution of phenol in $0.5 \mathrm{M} \mathrm{KOH}$ for EG after its anodic regeneration at the potential of $1.3 \mathrm{~V}$ in $4 \mathrm{M} \mathrm{KOH} \mathrm{(sample} \mathrm{EG-F-4AR-1.3).} \mathrm{Cycle} 1$ (straight line), cycle 2 (dashed line), and cycle 3 (dotted line). Potential range: $E_{\mathrm{R}} \leftrightarrow 0.8 \mathrm{~V}$ vs. $\mathrm{Hg} / \mathrm{HgO} / 0.5 \mathrm{KOH}$ 


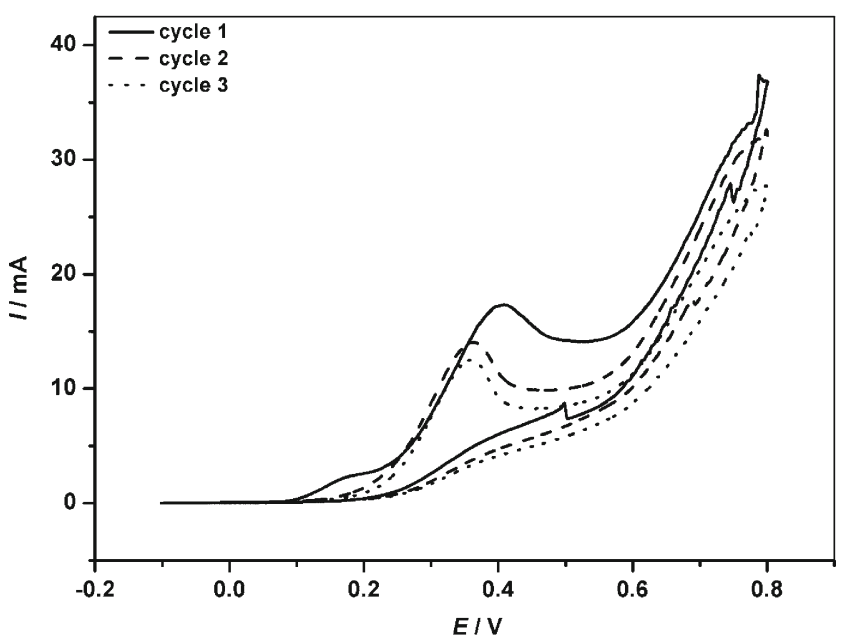

Fig. 4 Voltammetric curves recorded in $0.1 \mathrm{M}$ solution of phenol in $0.5 \mathrm{M} \mathrm{KOH}$ for $\mathrm{EG}$ after its anodic regeneration at the potential of $1.3 \mathrm{~V}$ in $6 \mathrm{M} \mathrm{KOH}$ (sample EG-F-6AR-1.3). Cycle 1 (straight line), cycle 2 (dashed line), and cycle 3 (dotted line). Potential range: $E_{\mathrm{R}} \leftrightarrow 0.8 \mathrm{~V}$ vs. $\mathrm{Hg} / \mathrm{HgO} / 0.5 \mathrm{KOH}$

oxidation reactions of phenol and/or products of its previous oxidation in this case proceed under dynamic conditions most likely caused by the formation of $\mathrm{CO}_{2}$ followed by its evolution. It cannot be excluded that also the decomposition of water accompanied by the oxygen evolution occurs in parallel. The probable occurrence of both reactions in the first cycle has the influence on the increased electrochemical activity of regenerated sample EG-F-6AR-1.3 exhibited during the second and third cycles.

Based on our experience in cathodic reactivation of exhausted EG [15], it is reasonable to assume that on considering the reasons of high efficiency attained for anodic regeneration of spent EG electrodes, the main attention should be focused on the interactions between active oxygen formed electrochemically and the layer of oligomer present on the EG surface. Oxygen generated violently due to electrochemical decomposition of water occurring during anodic regeneration may be recognized as an important regenerating factor. Besides oxygen, the electrolysis of aqueous solution of $\mathrm{KOH}$ may also generate hydroxyl radicals which can be considered as the other regenerating agents during the anodic treatment of EG/ oligomer. The reactions of these active agents with oligomer film appear to have both physical and chemical characters. Oxygen liberating intensively during regeneration at $1.3 \mathrm{~V}$ leads to a partial tearing of oligomer film followed by its removal from the EG surface. Such a behavior agrees with the literature data that report on the possibility of physical decomposition of polymeric layer due to oxygen evolution $[16,17]$. As a consequence of the oxygen attack on the EG/ oligomer, the porosity of a covering layer of oligomer products increases, thereby enabling the penetration of phenol molecules to active surface of EG which results in the enhancement of electrochemical activity of EG after its anodic regeneration.
Figure 5 displays cyclic voltammograms for sample EG recorded during the first cycle in $0.5,4$, and $5 \mathrm{M} \mathrm{KOH}$ solutions free of phenol at the potential range $-0.95 \leftrightarrow$ $0.8 \mathrm{~V}$ at a scan rate of $0.1 \mathrm{mV} / \mathrm{s}$. Similar to electrochemical measurements performed in phenol containing electrolytes, the experiments in phenol-free solutions were started from the rest potential of electrode towards the positive potentials. After starting the measurements, one can observe a long and flat part of voltammetric curve followed by a steep increase in anodic current. This effect is associated with the process of water decomposition accompanied by the intensive evolution of oxygen. In accordance with thermodynamic data, the reaction of water decomposition commences at lower potential as the solution concentration is higher.

To gain the information on chemical changes of the EG surface due to its anodic treatment in electrolytes of different concentrations of $\mathrm{KOH}$, the potential range was extended to $-0.95 \mathrm{~V}$. Such a mode of the measurement enabled the examination of cathodic effects related to the reduction of surface oxygen complexes originally present on the EG surface and those produced on the EG surface during preceded anodic polarization. Concerning all the three voltammetric curves shown in Fig. 5, the couple of cathodic current peaks arising from the reduction reactions of electrode surface (see inset) is seen. The potential position and intensity of these peaks differ significantly, depending on the concentration of $\mathrm{KOH}$ in the electrolyte used for investigations. The distinct difference in cathodic peak positions may suggest that the EG surface is modified depending on the concentration of $\mathrm{KOH}$ solution. On the other hand, the increased intensity of cathodic peaks noted for the EG samples examined in 4 and $6 \mathrm{M} \mathrm{KOH}$ justifies the assumption that the increased concentration of $\mathrm{KOH}$ employed during anodic oxidation of EG favors the formation of enhanced amount of surface oxygen

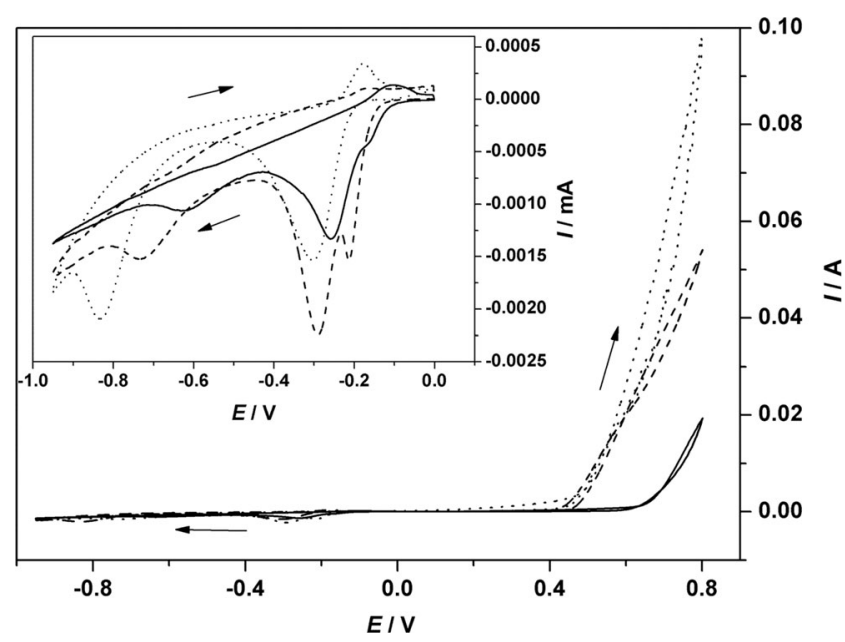

Fig. 5 Voltammetric curves recorded for EG in $0.5 \mathrm{M} \mathrm{KOH}$ solution (straight line), $4 \mathrm{M} \mathrm{KOH}$ solution (dashed line), and $6 \mathrm{M} \mathrm{KOH}$ solution (dotted line). Potential range $-0.95 \leftrightarrow 0.8 \mathrm{~V}$, inset: potential range $0 \leftrightarrow$ $-0.95 \mathrm{~V}$ 
functionalities. It is also seen that cathodic peak related to the complete removal of oxygen complexes from the carbon surface is noted at the lowest potential for $6 \mathrm{M} \mathrm{KOH}$ solution.

The effects of electrochemical oxidation on the structure and morphology of regenerated EG

The scenario proposed above is supported by the BET data obtained for the original and regenerated samples of EG. The specific surface area of $30.5 \mathrm{~m}^{2} \mathrm{~g}^{-1}$ for the original EG decreased markedly to $7.1 \mathrm{~m}^{2} \mathrm{~g}^{-1}$ for sample EG-F due to the formation of an oligomer layer during 3 cycles of phenol oxidation, and after regeneration treatment, it increased in turn to $14.8,21.1$, and $22.5 \mathrm{~m}^{2} \mathrm{~g}^{-1}$ for samples EG-F-0.5AR-1.3, EG-F-4AR-1.3, and EG-F-6AR-1.3, respectively. The comparison of these numbers with those depicted in Table 1 allows the noticing of the coincidence between the gradual development of BET surface due to anodic regeneration and the restoration of electrochemical activity. Sample EG-F-6AR1.3 of the highest specific surface area exhibited the greatest improvement of electrochemical activity towards phenol oxidation. To verify whether the BET surface is the only factor determining electrochemical activity, in Table 2, we gathered the current charges in relation to specific surface area. It is clearly seen from this table that electrochemical activity of all the regenerated EG related to the unit of surface area (expressed as current charge density) is much higher compared to the original EG. From this comparison, one can infer that the chemical composition of the carbon surface plays a dominant role in the enhancement of electrochemical activity. This conclusion is consistent with the results of the FTIR and XPS measurements (see below).

From the SEM observations, it is evidenced that the anodic regeneration of EG also contributes to the modification of its morphology. The SEM images depicted in Fig. 6 provide information on the presence of oligomer layer on the EG surface (Fig. 6b) as well as on the partial restoration of its surface properties due to advanced oxidation proceeded during regeneration treatment (Fig. 6c). As can be seen, after 3 cycles of phenol electrooxidation, the accordion-like structure of original EG (Fig. 6a) is completely coated with the tightly packed layer of oligomer (Fig. 6b). The regeneration process performed for $2 \mathrm{~h}$ at the potential of $1.3 \mathrm{~V}$ in electrolyte containing $6 \mathrm{M} \mathrm{KOH}$ leads to the removal of oligomer from the EG surface resulting in the uncovering of surface defects and edges (Fig. 6c) that played a role of catalytically active centers.

\section{Study of chemical composition of regenerated EG}

Owing to high activity of evolved oxygen as well as radical compounds (hydroxyl, oxygen) likely formed during the process of anodic regeneration, the chemical reactions between the mentioned agents and oligomer layer leading to its modification were expected. In order to verify the abovementioned hypothesis, the examination of chemical composition of regenerated EG surfaces by the FTIR and XPS analyses was performed.

Figure 7 displays a set of FTIR spectra recorded for all the spent EG electrodes after their anodic regeneration in comparison with spectra for the original EG and sample EG after 3 cycles of phenol oxidation (denoted EG-F). Since the most pronounced effects of regeneration appear within the frequency range of $400-2,000 \mathrm{~cm}^{-1}$, to improve the visibility of the most important signals, the spectra in Fig. 7 are shown in a shortened form. The particular comparison of the spectra reveals some differences in chemical composition of the sample surfaces caused by regeneration treatment. Among them, the appearance of a new band within the frequency of 1 , $580 \mathrm{~cm}^{-1}$ and the significant changes in a broad band in the wave number regions $1,633-1,647$ and $1,425-1,451 \mathrm{~cm}^{-1}$ observed for regenerated EG (Fig. 7(c-e)) seem to be of high importance. According to the literature data, the new band can be assigned to the stretching vibration of $\mathrm{C}=\mathrm{O}$ within the
Table 2 Anodic charge densities for original EG and EG/oligomer after their anodic regeneration calculated in relation to specific surface area

\begin{tabular}{|c|c|c|c|c|c|c|c|}
\hline \multirow[t]{2}{*}{ Sample } & \multirow[t]{2}{*}{ Figure } & \multirow{2}{*}{$\begin{array}{l}\text { Preparation } \\
\text { conditions }\end{array}$} & \multirow{2}{*}{$\begin{array}{l}\text { BET surface area } \\
\left(\mathrm{m}^{2} \mathrm{~g}^{-1}\right)\end{array}$} & \multicolumn{4}{|c|}{ Anodic charge density $\left(\mathrm{As} \mathrm{m}^{-2}\right)$} \\
\hline & & & & $\begin{array}{l}\text { Cycle } \\
1\end{array}$ & $\begin{array}{l}\text { Cycle } \\
2\end{array}$ & $\begin{array}{l}\text { Cycle } \\
3\end{array}$ & $\begin{array}{l}\text { Cycles } \\
1-3\end{array}$ \\
\hline $\begin{array}{l}\text { Original } \\
\text { EG }\end{array}$ & 1 & & 30.5 & 44.3 & 25.3 & 21.3 & 90.9 \\
\hline $\begin{array}{l}\text { EG-F- } \\
\begin{array}{l}0.5 \mathrm{AR}- \\
1.3\end{array}\end{array}$ & 2 & $\begin{array}{l}\text { EG/oligomer after } \\
\text { regeneration at } 1.3 \\
\mathrm{~V} \text { in } 0.5 \mathrm{M} \mathrm{KOH}\end{array}$ & 14.8 & 227.0 & 147.4 & 117.6 & 492.0 \\
\hline $\begin{array}{l}\text { EG-F- } \\
\quad 4 \text { AR- } \\
1.3\end{array}$ & 3 & $\begin{array}{l}\text { EG/oligomer after } \\
\text { regeneration at } 1.3 \\
\mathrm{~V} \text { in } 4 \mathrm{M} \mathrm{KOH}\end{array}$ & 21.1 & 228.8 & 179.0 & 157.4 & 565.2 \\
\hline $\begin{array}{l}\text { EG-F- } \\
\text { 6AR- } \\
1.3\end{array}$ & 4 & $\begin{array}{l}\text { EG/oligomer after } \\
\text { regeneration at } 1.3 \\
\mathrm{~V} \text { in } 6 \mathrm{M} \mathrm{KOH}\end{array}$ & 22.5 & 299.9 & 248.0 & 217.1 & 765.0 \\
\hline
\end{tabular}



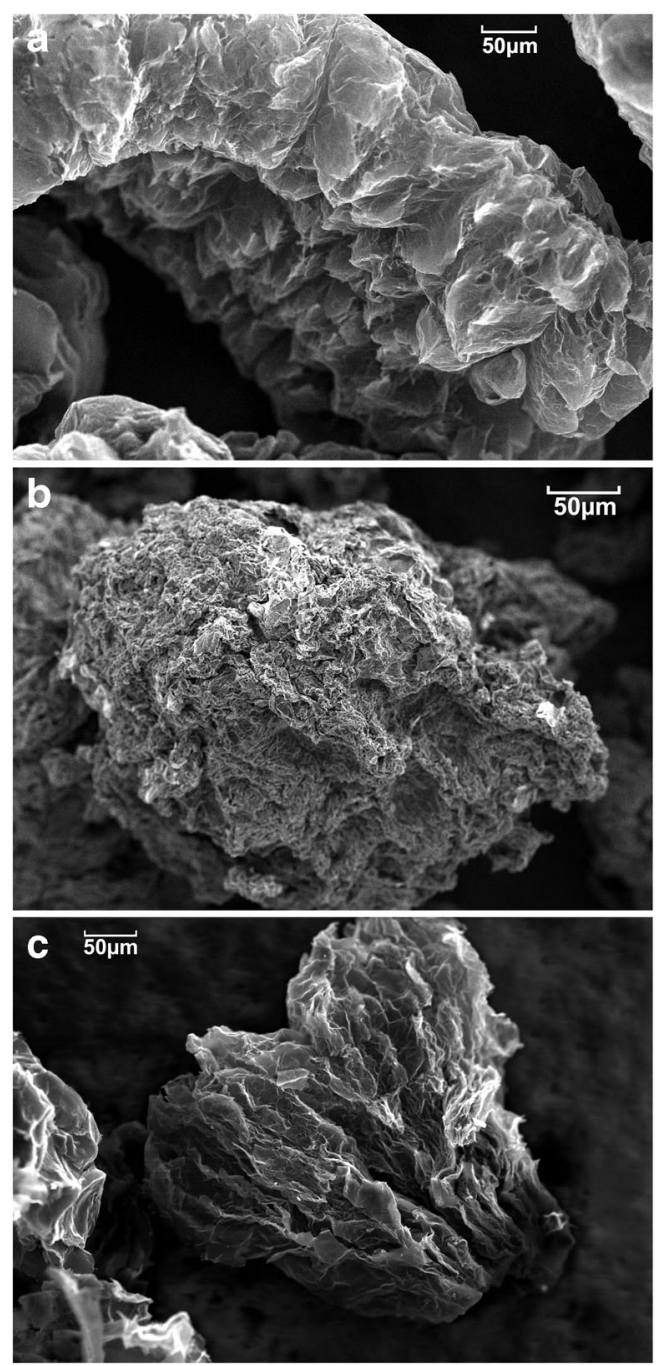

Fig. 6 SEM images for the original EG (a), EG after 3 cycles of phenol electrooxidation (b), EG after its anodic regeneration at the potential of $1.3 \mathrm{~V}$ in $0.5 \mathrm{M} \mathrm{KOH}(\mathrm{EG}-\mathrm{F}-0.5 \mathrm{AR}-1.3)(\mathbf{c})$

aromatic structures or in conjugated systems like diketone [27-29]. A broad band at 1,633-1,647 $\mathrm{cm}^{-1}$ for EG regenerated in $6 \mathrm{M} \mathrm{KOH}$ consists of two maxima, whereas for the rest of samples had only one maximum that appeared at 1 , $633 \mathrm{~cm}^{-1}$. The regarded signals can be ascribed to $\mathrm{C}=\mathrm{O}$ bonds pertaining to quinine groups $[29,30]$ but also to ion radical structures [29]. Taking into consideration the conditions of oxidative regeneration, the latter assignment seems to be especially worth noting because it partially confirms the formation of active radical compounds formed due to anodic regeneration. It should be emphasized that the contribution of the band in the wave number region of $1,633-1,647 \mathrm{~cm}^{-1}$ in the entire spectrum of sample EG-F-6AR-1.3 regenerated in $6 \mathrm{M} \mathrm{KOH} \mathrm{(Fig.} \mathrm{7(e))} \mathrm{is} \mathrm{considerably} \mathrm{higher} \mathrm{as} \mathrm{compared} \mathrm{to}$ the spectra for samples regenerated in $0.5 \mathrm{M} \mathrm{KOH}$ (Fig. 7(c)) and $4 \mathrm{M} \mathrm{KOH} \mathrm{(Fig.} \mathrm{7(d)),} \mathrm{respectively.} \mathrm{On} \mathrm{FTIR} \mathrm{spectra}$ shown in Fig. 7, one can also observe a characteristic broad band appearing at the frequency region of $1,425-1,451 \mathrm{~cm}^{-1}$

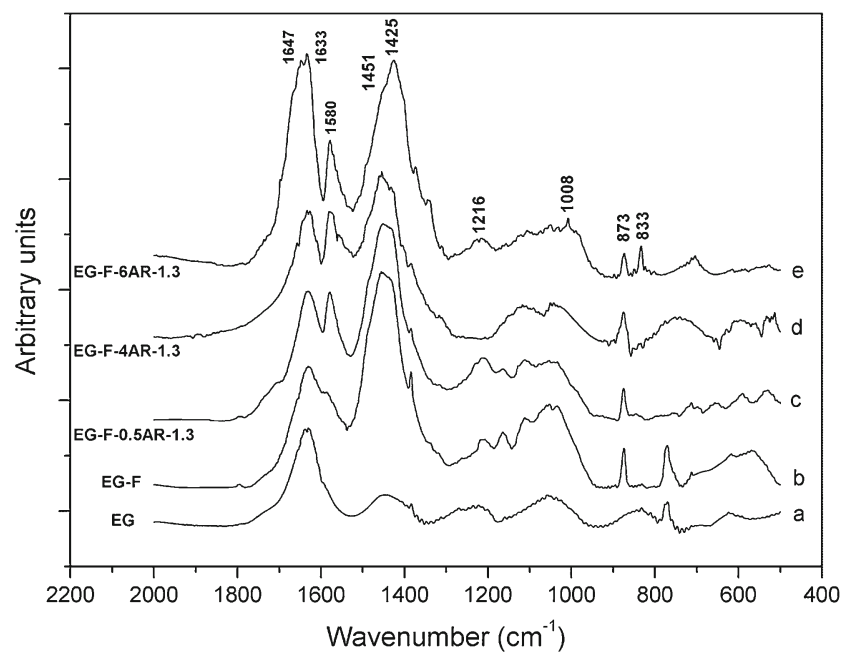

Fig. 7 FTIR spectra recorded for the original EG $(a)$, EG after 3 cycles of phenol electrooxidation $(b)$, EG after its anodic regeneration at the potential of $1.3 \mathrm{~V}$ in $0.5 \mathrm{M} \mathrm{KOH}$ (EG-F-0.5AR-1.3) (c), EG after its anodic regeneration at the potential of $1.3 \mathrm{~V}$ in $4 \mathrm{M} \mathrm{KOH} \mathrm{(EG-F-4AR-}$ 1.3) $(d)$, and $\mathrm{EG}$ after its anodic regeneration at the potential of $1.3 \mathrm{~V}$ in $6 \mathrm{M} \mathrm{KOH}($ EG-F-6AR-1.3) (e)

most likely associated with the stretching vibrations arising from the carbonated structures $[28,31]$. The character of this band changes depending on the type of sample. The regarded band includes two maxima with the exception of the sample regenerated in $6 \mathrm{M} \mathrm{KOH}$ (sample EG-F-6AR-1.3) for which only one maximum is recorded at $1,425 \mathrm{~cm}^{-1}$. The results of FTIR clearly indicate that a strong oxidative treatment of regenerated EG/oligomer composite carried out under conditions of violent oxygen evolution markedly changes its surface also in terms of chemical composition. The increased number of different carbon structures involving $\mathrm{C}=\mathrm{O}$ bonds and the formation of radical systems make the regenerated samples considerably more active compared to the original EG. Because the most significant changes in chemical composition were noted for EG regenerated in $6 \mathrm{M} \mathrm{KOH}$ (sample EG-F-6AR-1.3), this sample was chosen for further investigations.

The XPS analysis of regenerated EG/oligomer revealed unexpected results. As compared to sample EG-F, total oxygen content determined from the O1s spectra (Fig. 8) shows the considerable decrease in oxygen surface concentration due to anodic regeneration (sample EG-F-6AR-1.3). As seen from Table 3, the total oxygen content for regenerated sample is almost twice lower compared to the sample EG coated with oligomer (EG-F-sample subjected to regeneration). Based on the quantitative data of $\mathrm{O} 1 \mathrm{~s}$ spectrum for the sample EG-F6AR-1.3, one can notice that the lowering of oxygen surface concentrations due to regeneration treatment of spent EG (Fig. 8c) is mainly related to the decrease in intensity of peaks B and D and with the disappearance of peak A. Signal B at the binding energy of $531.5 \mathrm{eV}$ corresponds to $\mathrm{K}-\mathrm{O}$ species [32], whereas peak $\mathrm{D}$ at $533.8 \mathrm{eV}$ arises from oxygen singly bounded to carbon [27, 33]. Besides the described diminution in 

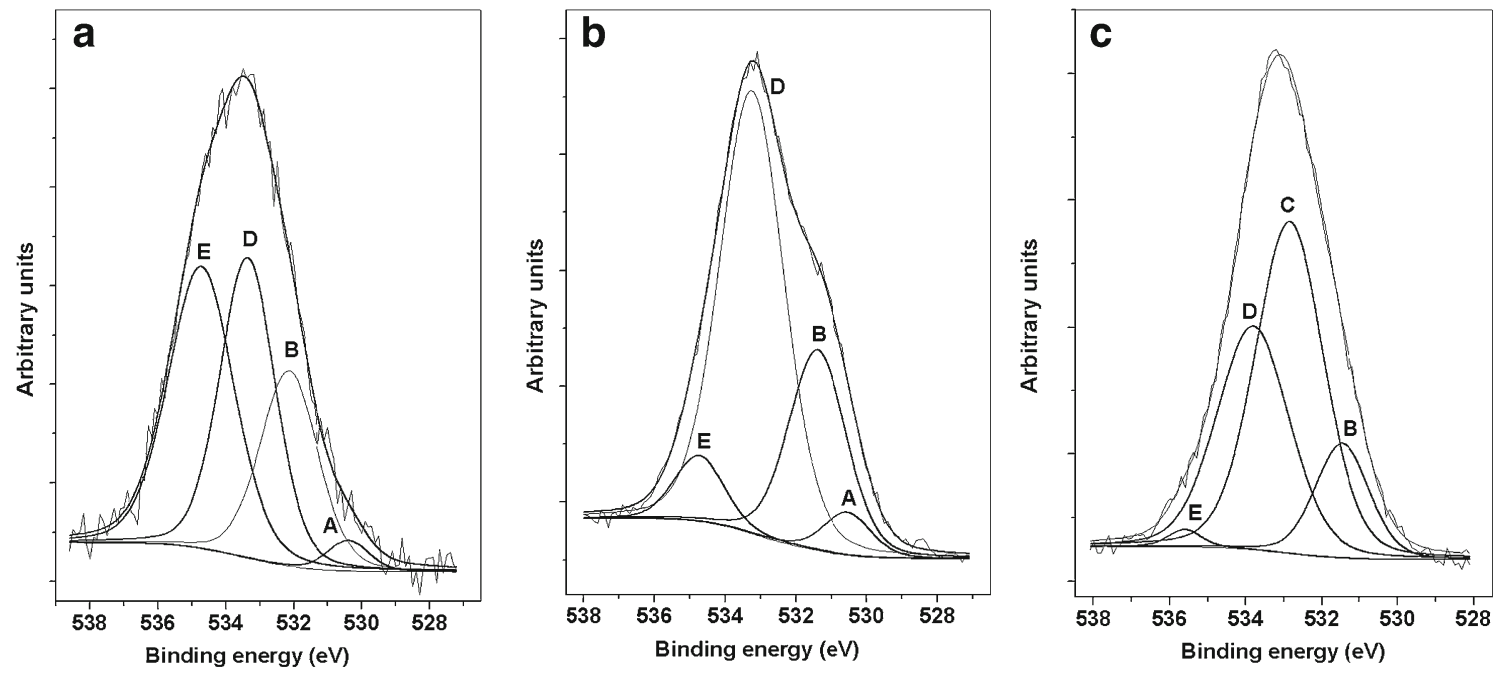

Fig. 8 O 1 s spectra of the original EG (a), EG after 3 cycles of phenol electrooxidation (b), and EG after its anodic regeneration at the potential of $1.3 \mathrm{~V}$ in $6 \mathrm{M} \mathrm{KOH}(\mathrm{EG}-\mathrm{F}-6 \mathrm{AR}-1.3)(\mathbf{c})$

intensity of peaks $\mathrm{B}$ and $\mathrm{D}$, on the $\mathrm{O} 1 \mathrm{~s}$ spectrum for regenerated EG (sample EG-F-6AR-1.3), a new peak appears at the binding energy of $532.8 \mathrm{eV}$ (peak C) (Fig. 8c). The regarded signal can be ascribed to the $\mathrm{C}=\mathrm{O}$ bonds [27, 33]. The comparison of $\mathrm{O} 1 \mathrm{~s}$ spectra recorded for EG/oligomer composite before (Fig. 8b) and after regeneration (Fig. 8c) indicates that the chemical composition of oligomer changed due to anodic treatment. The oligomer chain becomes enriched in $\mathrm{C}=\mathrm{O}$ bonds with simultaneous impoverishment of $\mathrm{C}-\mathrm{O}$ bonds.

The explanation that the concentration of surface species composed of singly bounded oxygen decreases along with the enrichment of the surface of regenerated EG/oligomer composite in the $\mathrm{C}=\mathrm{O}$ species is consistent with the $\mathrm{C} 1 \mathrm{~s}$ spectra shown in Fig. 9. As can be seen in Table 3, the concentration of $\mathrm{C}-\mathrm{O}$ bonds represented by peak $\mathrm{B}(285.3 \mathrm{eV})$ decreases after anodic regeneration (Fig. 9c) [27,33]. On the other hand, the concentration of the surface groups mainly composed of carbon double bonded with oxygen increases after oxidative regeneration. According to the $\mathrm{C} 1 \mathrm{~s}$ spectra analysis, $\mathrm{C}=\mathrm{O}$ bonds pertaining to carboxylic, ester functionalities are formed (peak D) $[27,33]$ and the concentration of $\mathrm{C}=\mathrm{O}$ bonds within the carbonyl, quinone group of almost $60 \%$ increases (peak C) on the surface of EG/oligomer due to its strong oxidative regenerating treatment. If we assume that active oxygen makes the oligomer more porous, one can expect that the chemical composition of the subsurface graphitic atoms becomes more active due to the formation of oxygen functional groups. Indeed, the XPS data gathered in Table 3 and Fig. 9c display a new signal $\mathrm{D}$ at the binding energy of $288.6 \mathrm{eV}$ related to the $\mathrm{C}=\mathrm{O}$ bonds in carboxylic or/and ester groups [27,33]. This feature agrees with the above hypothesis that the modified carbon surface of a higher electrochemical activity is formed as an effect of potentiostatic oxidation of EG coated with oligomer.

Table 3 XPS results: surface composition of original EG and EG/oligomer before and after their anodic regeneration

\begin{tabular}{|c|c|c|c|c|c|c|c|c|c|c|}
\hline \multirow[t]{2}{*}{ Spectrum } & \multirow[t]{2}{*}{ Peaklsample } & \multicolumn{3}{|l|}{ EG } & \multicolumn{3}{|l|}{ EG-F } & \multicolumn{3}{|c|}{ EG-F-6R-1.3 } \\
\hline & & $(\mathrm{eV})$ & (at.\%) & Total content (at.\%) & $(\mathrm{eV})$ & (at.\%) & Total content (at.\%) & $(\mathrm{eV})$ & (at.\%) & Total content (at.\%) \\
\hline \multirow[t]{5}{*}{$\mathrm{O} 1 \mathrm{~s}$} & A & 530.4 & 0.09 & \multirow[t]{5}{*}{3.35} & 530.6 & 0.94 & \multirow[t]{5}{*}{13.05} & & & \multirow[t]{5}{*}{7.67} \\
\hline & $\mathrm{B}$ & 532.1 & 0.8 & & 531.6 & 3.42 & & 531.5 & 1.05 & \\
\hline & $\mathrm{C}$ & & & & & & & 532.8 & 3.8 & \\
\hline & $\mathrm{D}$ & 533.4 & 1.16 & & 533.3 & 7.83 & & 533.8 & 2.72 & \\
\hline & $\mathrm{E}$ & 534.7 & 1.3 & & 534.8 & 0.86 & & 535.6 & 0.1 & \\
\hline \multirow[t]{5}{*}{$\mathrm{C} 1 \mathrm{~s}$} & $\mathrm{~A}$ & 284.6 & 61.12 & \multirow[t]{5}{*}{96.65} & 284.6 & 47.27 & \multirow[t]{5}{*}{86.95} & 284.6 & 45.57 & \multirow[t]{5}{*}{92.33} \\
\hline & B & 285.9 & 20.7 & & 286.0 & 27.98 & & 285.3 & 26.96 & \\
\hline & $\mathrm{C}$ & 287.3 & 8.27 & & 287.4 & 8.23 & & 286.7 & 13.12 & \\
\hline & $\mathrm{D}$ & & & & & & & 288.6 & 2.64 & \\
\hline & $\mathrm{E}$ & 290.7 & 6.56 & & 289.8 & 3.47 & & 291.0 & 4.04 & \\
\hline
\end{tabular}



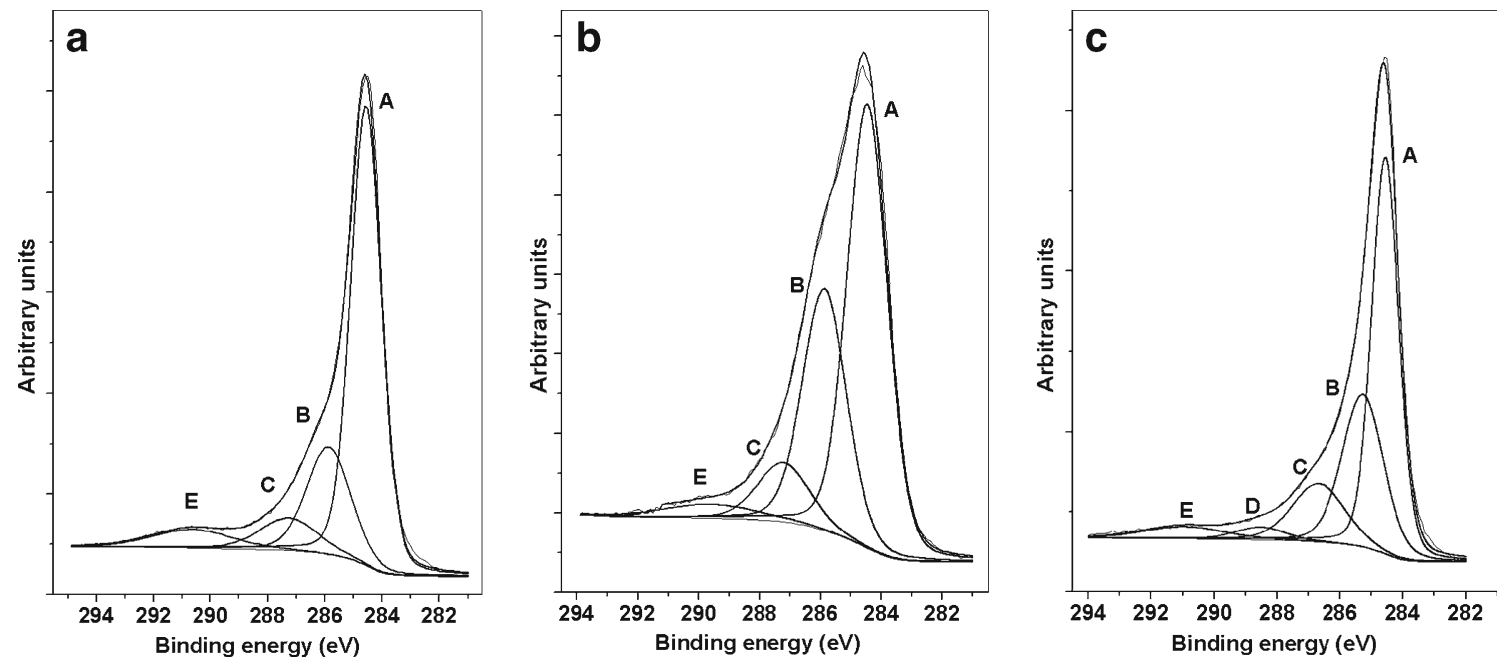

Fig. 9 C 1 s spectra of the original EG (a), EG after 3 cycles of phenol electrooxidation (b), and EG after its anodic regeneration at the potential of $1.3 \mathrm{~V}$ in $6 \mathrm{M} \mathrm{KOH}(\mathrm{EG}-\mathrm{F}-6 \mathrm{AR}-1.3)$ (c)

The XPS observations coincide with those obtained from the FTIR analysis and justify the conclusion that the oxidative treatment of oligomer performed under conditions of intensive oxygen evolution mainly results in the generation or/and transformation of existing systems into $\mathrm{C}=\mathrm{O}$ species.

To explain the particular role of $\mathrm{KOH}$ concentration in the efficiency of EG/oligomer anodic regeneration, the electrochemical experiments were performed in such that the concentration of regeneration electrolyte varied from 1.1 to $1.4 \mathrm{~V}$. Due to very low activity demonstrated by sample EG that was regenerated for $2 \mathrm{~h}$ at the potentials of 1.1 and $1.4 \mathrm{~V}$, the attained CVs are not shown here. In the case of the process occurring at $1.1 \mathrm{~V}$, the used conditions appeared to be too mild to ensure the complete restoration of EG activity. On the other hand, the potential of regeneration adjusted to $1.4 \mathrm{~V}$ was too high because the process of intensive oxygen evolution caused a very strong oxidation of regenerated electrode, leading to its destruction demonstrated by the considerable loss of regenerated material. The disintegration of EG electrode accompanied by the considerable decrease in electrochemical activity makes the described treatment almost completely useless from the point of view of EG regeneration. The CVs recorded during the electrochemical oxidation of phenol at the electrode made of spent EG subjected beforehand to anodic regeneration in $6 \mathrm{M} \mathrm{KOH}$ at the potential of $1.2 \mathrm{~V}$ (sample EG-F-6AR1.2) are displayed in Fig. 10. From this figure, it is evident that the regeneration process at the potential of $1.2 \mathrm{~V}$ is profitable for restoration of the starting EG activity but seems to be unsatisfactory to reach the electrochemical activity level observed for the sample after its regeneration in $6 \mathrm{M} \mathrm{KOH}$ at $1.3 \mathrm{~V}$ (Table 1). On the basis of these results, one can point out that the highest improvement of electrochemical activity of regenerated EG is attained when a faster generation of active oxygen occurs.
Electrochemical oxidation of phenol on EG after three regeneration loops

The goal of the last part of the present investigations was to study the possibility of multiple electrochemical regeneration of spent EG electrode by estimating its usefulness in the technological process consisting of phenol electrooxidation followed by instantly performed anodic regeneration. For this purpose, three regenerating loops composed of repeated sequence of operation involving 3 cycles of phenol electrooxidation and anodic treatment of EG electrode in $6 \mathrm{M} \mathrm{KOH}$ for $2 \mathrm{~h}$ at the potential of 1.2 or $1.3 \mathrm{~V}$ were performed. To discuss issues concerning multiple

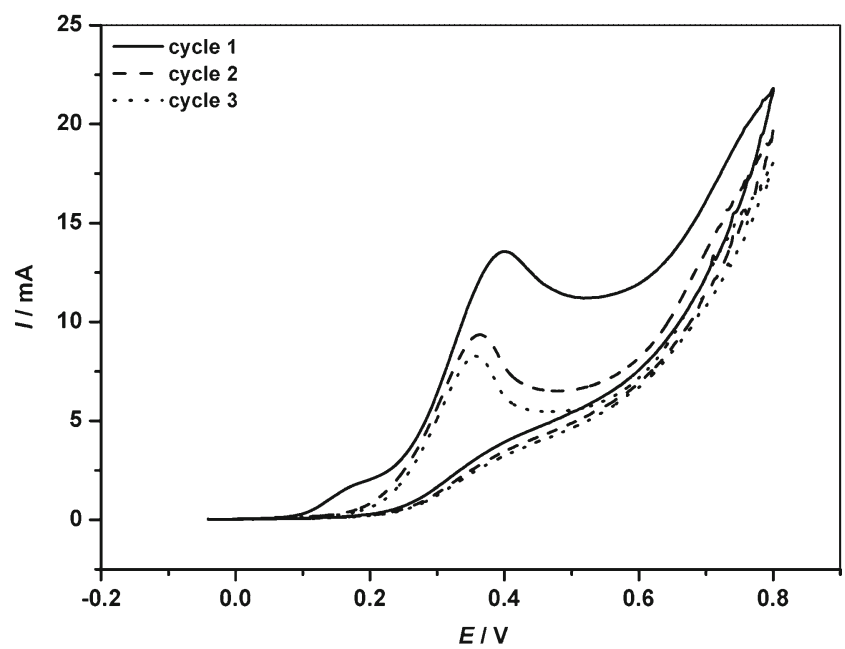

Fig. 10 Voltammetric curves recorded in $0.1 \mathrm{M}$ solution of phenol in $0.5 \mathrm{M} \mathrm{KOH}$ for EG after its anodic regeneration at the potential of $1.2 \mathrm{~V}$ in $6 \mathrm{M} \mathrm{KOH}$ (sample EG-F-6AR-1.2). Cycle 1 (straight line), cycle 2 (dashed line), and cycle 3 (dotted line). Potential range: $E_{\mathrm{R}} \leftrightarrow 0.8 \mathrm{~V}$ vs. $\mathrm{Hg} / \mathrm{HgO} / 0.5 \mathrm{KOH}$ 
regeneration, we decided to present in Figs. 11 and 12 the CVs depicting the processes of phenol electrooxidation carried out after the third reactivation loop in which the regenerating treatments were conducted at potentials of $1.3 \mathrm{~V}$ (sample EG-F-6AR-1.3×3) and 1.2 V (sample EG-F-6AR-1.2×3), respectively. The comprehensive information on electrochemical behavior of EG electrode after its multiple anodic regenerations can be given from the comparison of the intensities and peak charges calculated during the processes of phenol electrooxidation carried out instantly after the consecutive regeneration treatments (Table 1). Taking into consideration the first and successive cycles of phenol oxidation on EG repeatedly regenerated at $1.3 \mathrm{~V}$ (Figs. 4 and 11), it can be pointed out that the electrochemical activity decreases gradually with the number of reactivating loops (Table 1 ). Contrary to the regeneration treatments proceeded at $1.3 \mathrm{~V}$, in the case of multiple regeneration of spent EG performed at a lower potential (1.2 V; Fig. 12), the electrochemical activity considerably increases after consecutive regenerating loops, reaching higher values of anodic charge compared to the sample after multiple regeneration at $1.3 \mathrm{~V}$ (Fig. 11). The differences in potential position and shape of phenol oxidation peak justify the assumption that the anodic regenerations of EG at 1.2 and $1.3 \mathrm{~V}$ proceed according to different mechanisms. From the comparison of $\mathrm{CV}$ curves recorded for electrodes regenerated at $1.3 \mathrm{~V}$ (Figs. 4 and 11) and $1.2 \mathrm{~V}$ (Figs. 10 and 12), it is clearly seen that the maximum of phenol oxidation peak is shifted at about $90 \mathrm{mV}$ to positive potentials for electrodes regenerated at lower potential. Simultaneously, the regarded peak for this sample is narrower and more symmetric. It means that in this case, the reaction of phenol electrooxidation takes place at the surface of different porosity

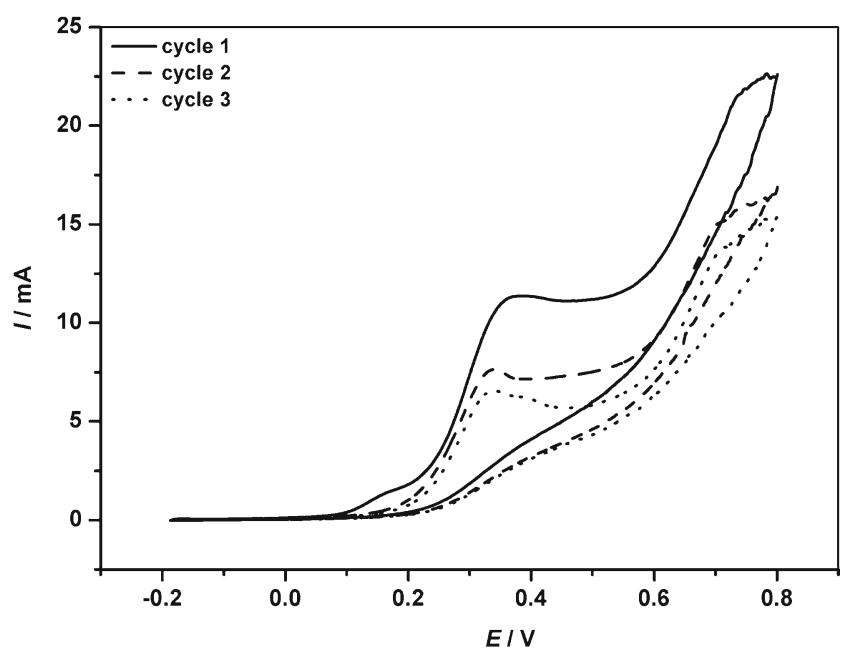

Fig. 11 Voltammetric curves recorded in $0.1 \mathrm{M}$ solution of phenol in $0.5 \mathrm{M} \mathrm{KOH}$ for EG after three regeneration loops at the potential of $1.3 \mathrm{~V}$ in $6 \mathrm{M} \mathrm{KOH}$ (sample EG-F-6AR-1.3×3). Cycle 1 (straight line), cycle 2 (dashed line), and cycle 3 (dotted line). Potential range: $E_{\mathrm{R}} \leftrightarrow 0.8 \mathrm{~V}$ vs. $\mathrm{Hg} / \mathrm{HgO} / 0.5 \mathrm{KOH}$

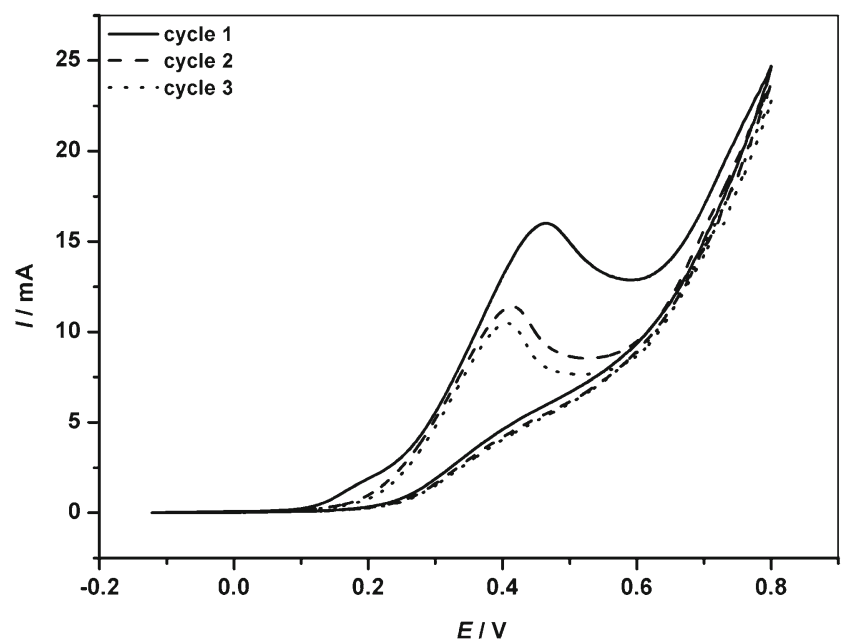

Fig. 12 Voltammetric curves recorded in $0.1 \mathrm{M}$ solution of phenol in $0.5 \mathrm{M} \mathrm{KOH}$ for EG after three regeneration loops at the potential of $1.2 \mathrm{~V}$ in $6 \mathrm{M} \mathrm{KOH} \mathrm{(sample} \mathrm{EG-F-6AR-1.2×3).} \mathrm{Cycle} 1$ (straight line), cycle 2 (dashed line), and cycle 3 (dotted line). Potential range: $E_{\mathrm{R}} \leftrightarrow 0.8 \mathrm{~V}$ vs. $\mathrm{Hg} / \mathrm{HgO} / 0.5 \mathrm{KOH}$

and chemical properties. The presence of some irregularities on CVs within the potential range of $0.55-0.8 \mathrm{~V}$ for EG/ oligomer anodically treated at $1.3 \mathrm{~V}$ can be assigned to the reaction of gas evolution. This effect probably is associated with the entire phenol oxidation with the formation of final products $\left(\mathrm{CO}_{2}\right.$ and $\left.\mathrm{H}_{2} \mathrm{O}\right)$, but it cannot be excluded that it also arises from the destruction of the electrode material caused by its strong oxidation accompanied by oxygen evolution. The above-mentioned hypothesis is partially confirmed by an approximately $10 \%$ loss of electrode material occurring after three regenerating loops involving anodic treatments at $1.3 \mathrm{~V}$ (sample EG-F-6AR-1.3×3). This disadvantageous effect was not observed in the case of sample EG-F-6AR-1.2 $\times 3$. On the basis of the obtained results, it can be pointed out that from the point of view of a single operation of anodic regeneration of spent EG electrode the anodic treatment in $6 \mathrm{M} \mathrm{KOH}$ at the potential of $1.3 \mathrm{~V}$ appears to be worthy of practical interest. On the other hand, regarding the multiple regeneration of exhausted EG, anodic treatment at potential of $1.2 \mathrm{~V}$ appears to be a more effective method for the restoration of EG properties and simultaneously more resistant to the decomposition.

\section{Conclusions}

Due to a common feature of various electrodes used for electrochemical oxidation of phenol consisting in an abrupt deactivation of electrode material caused by the deposition of oligomer, there is the need for the development of methods of electrode regeneration. The present investigations on the anodic regeneration of exfoliated graphite exhausted by 
oligomeric products of incomplete phenol electrooxidation can be summarized as follows:

1. Anodic regeneration of exfoliated graphite spent during the electrooxidation of phenol results not only in the restoration but also in an enormous enhancement of its primary activity.

2. Enhanced activity of regenerated EG resulted from the modification of structural and morphological properties as well as chemical composition of its surface.

3. It has been shown for the first time that the method of anodic regeneration of spent EG enables the electrode to be repeatedly used without both the decline in electrochemical activity and mass loss.

Taking into account the anodic charges noted during the electrooxidation of phenol as a main criterion for estimating electrochemical activity, it can be pointed out that a single-step anodic treatment carried out in $6 \mathrm{M} \mathrm{KOH}$ at the potential of $1.3 \mathrm{~V}$ ensuring a violent oxygen evolution allows reaching the highest efficiency of spent EG regeneration. Under such conditions, the electrochemical activity of the regenerated sample measured for the first cycle is almost fivefold higher than that for the original EG.

During the anodic regeneration performed under strong oxidative conditions, the intensive process of oxygen evolution is accompanied by the generation of active oxygen and/or $\mathrm{OH} \cdot$ radical. From the FTIR and XPS analyses, it is evident that the oxidative attack of these active agents on the oligomer layer covering the EG surface resulted in considerable modification of its chemical composition. Due to anodic regeneration of EG/oligomer the enhancement of surface functionalities, mainly composed of $\mathrm{C}=\mathrm{O}$, occurs. Another important effect of anodic treatment of spent $\mathrm{EG}$ is the significant reduction of $\mathrm{C}-\mathrm{O}$ bonds within the covering oligomer film which results in the modification of its properties and chemical composition. The BET measurements of regenerated samples confirm our assumption that the physical modification of oligomer structure results in the development of specific surface area compared to EG before regeneration treatment. This conclusion is supported by the results of the SEM observations. As a consequence of a partial exposure of the EG/oligomer subsurface to the electrolyte, chemical modification of EG may also take place.

The studies concerning the possibility of a long-term recovery of electrochemical activity of exhausted EG disclosed experimental conditions in which electrode material is threatened with disintegration. If the oxidative treatment of EG/ oligomer performed in $6 \mathrm{M} \mathrm{KOH}$ at $1.3 \mathrm{~V}$ is repeated after the successive processes of phenol oxidation, the electrochemical activity of investigated electrode gradually decreases with the number of regenerating operations. This disadvantageous feature is tentatively assigned to a partial destruction of regenerated electrode due to too severe conditions of its oxidative treatment during the anodic regeneration. The abovementioned hypothesis is consistent with the investigations in which the potential used for multiple regeneration was lowered to $1.2 \mathrm{~V}$. In such a case, the electrochemical activity of EG that appeared to increase gradually with the number of regenerating loops and after the third regeneration was during the first cycle almost four-fold higher compared to that of the original EG. The obtained results showed that the multiple regeneration method is promising for practical applications because of the possible reduction of energy and material costs.

Open Access This article is distributed under the terms of the Creative Commons Attribution License which permits any use, distribution, and reproduction in any medium, provided the original author(s) and the source are credited.

\section{References}

1. Li XY, Cui YH, Feng YJ, Xie ZM, Gu JD (2005) Reaction pathways and mechanisms of the electrochemical degradation of phenol on different electrodes. Water Res 39:1972-1981

2. Gattrell M, Kirk DW (1992) A Fourier transformation infrared spectroscopy study of the passive film produced during aqueous acidic phenol electro-oxidation. J Electrochem Soc 139:2736-2744

3. Gattrell M, Kirk DW (1993) A study of electrode passivation during aqueous phenol electrolysis. J Electrochem Soc 140:903-911

4. Ureta-Zanartu MS, Bustos P, Diez MC, Mora ML, Gutiérrez C (2001) Electro-oxidation of chlorophenols at a gold electrode. Electrochim Acta 46:2545-2551

5. Andreescu S, Andreescu D, Sadik OA (2003) A new electrocatalytic mechanism for the oxidation of phenols at platinum electrodes. Electrochem Commun 5:681-688

6. Wu Z, Zhou M, Wang D (2002) Synergetic effects of anodic-cathodic electrocatalysis for phenol degradation in the presence of iron(II). Chemosphere 48:1089-1096

7. Feng YJ, Li XY (2003) Electro-oxidation of phenol on several metaloxide electrodes in aqueous solution. Water Res 37:2399-2407

8. Iniesta J, Michaud PA, Panizza M, Cerisola G, Aldaz A, Comninellis C (2001) Electrochemical oxidation of phenol at boron-doped diamond electrode. Electrochim Acta 46:3573-3578

9. Cañizares P, García-Gómez J, Sáez C, Rodrigo MA (2003) Electrochemical oxidation of several chlorophenols on diamond electrodes Part I. Reaction mechanism. J Appl Electrochem 33:917-927

10. Ureta-Zanartu MS, Bustos P, Berrios C, Diez MC, Mora ML, Gutiérrez C (2002) Electrooxidation of 2,4-dichlorophenol and other polychlorinated phenols at a glassy carbon electrode. Electrochim Acta 47:2399-2406

11. Kuramitz H, Nakata Y, Kawasaki M, Tanaka S (2001) Electrochemical oxidation of bisphenol A: application to the removal of bisphenol A using a carbon fiber electrode. Chemosphere 45:37-43

12. Skowroński JM, Krawczyk P (2004) Electrooxidation of phenol at exfoliated graphite electrode in alkaline solution. J Solid State Electrochem 8:442-447

13. Skowroński JM, Krawczyk P (2009) Enhanced electrochemical activity of regenerated expanded graphite electrode after exhaustion in the process of phenol oxidation. Chem Eng J 152:464-470

14. Krawczyk P, Skowroński JM (2010) Modification of expanded graphite resulting in enhancement of electrochemical activity in the process of phenol oxidation. J Appl Electrochem 40:91-98 
15. Krawczyk P, Skowroński JM (2012) Electrochemical reactivation of expanded graphite electrodes covered by oligomeric products of phenol electrooxidation. Electrochim Acta 79:202-209

16. Tahar NB, Savall A (2009) Electrochemical removal of phenol in alkaline solution: contribution of the anodic polymerization on different electrode materials. Electrochim Acta 54:48094816

17. Tahar NB, Savall A (2009) Electropolymerization of phenol on a vitreous carbon electrode in alkaline aqueous solution at different temperatures. Electrochim Acta 55:465-469

18. Salvador F, Sánchez Jiménez C (1996) A new method for regenerating activated carbon by thermal desorption with liquid water under subcritical conditions. Carbon 34:511-516

19. Chiang PC, Chung EE, Wu JS (1997) Comparison of chemical and thermal regeneration of aromatic compounds on exhausted activated carbon. Water Sci Technol 35:279-285

20. Rivera-Utrilla J, Ferro-Garciá MA, Bautista-Toledo I, SánchezJiménez C, Salvador F, Merchán MD (2003) Regeneration of ortho-chlorophenol-exhausted activated carbons with liquid water at high pressure and temperature. Water Res 37:1905-1911

21. Maroto-Valer MM, Dranca I, Clifford D, Lupascu T, Nastas R, Leon y Leon CA (2006) Thermal regeneration of activated carbons saturated with ortho- and meta-chlorophenols. Thermochim Acta 444: $148-156$

22. Toledo LC, Bernardes Silva AC, Augusti R, Lago RM (2003) Application of Fenton's reagent to regenerate activated carbon saturated with organochloro compounds. Chemosphere 50:1049-1054

23. Zhang H (2002) Regeneration of exhausted activated carbon by electrochemical method. Chem Eng J 85:81-85

24. Zhou MH, Lei LC (2006) Electrochemical regeneration of activated carbon loaded with p-nitrophenol in a fluidized electrochemical reactor. Electrochim Acta 51:4489-4496
25. Weng CH, Hsu MC (2008) Regeneration of granular activated carbon by an electrochemical process. Sep Purif Technol 64:227-236

26. Skowroński JM, Jurewicz K (1991) Anodic oxidation of CrO3graphite intercalation compounds in sulfuric acid. Synth Met 40: 161-172

27. Terzyk AP (2001) The influence of activated carbon surface chemical composition on the adsorption of acetaminophen (paracetamol) in vitro: Part II. TG, FTIR, and XPS analysis of carbons and the temperature dependence of adsorption kinetics at the neutral $\mathrm{pH}$. Colloids Surf A Physicochem Eng Asp 177:23-45

28. Jung SJ, Park WY (2002) Effect of KOH Activation on the formation of oxygen structure in activated carbons synthesized from polymeric precursor. J Colloid Interface Sci 250:93-98

29. Pakuła M, Świątkowski A, Walczyk M, Biniak S (2005) Voltammetric and FTIR studies of modified activated carbon systems with phenol, 4-chlorophenol or 1,4-benzoquinone adsorbed from aqueous electrolyte solutions. Colloids Surf A Physicochem Eng Asp 260:145-155

30. Ežerskis Z, Jusys Z (2002) Electropolymerization of chlorinated phenols on a Pt electrode in alkaline solution. Part III: a Fourier transformed infrared spectroscopy study. J Appl Electrochem 32:755-762

31. Lillo-Ródenas MA, Cazorla-Amoroós D, Linares-Solano A (2003) Understanding chemical reactions between carbons and $\mathrm{NaOH}$ and $\mathrm{KOH}$ : An insight into the chemical activation mechanism. Carbon 41:267-275

32. Díaz-Terán J, Nevskaia DM, Fierro JLG, López-Peinado AJ, Jerez A (2003) Study of chemical activation process of a lignocellulosic material with $\mathrm{KOH}$ by XPS and XRD. Microporous Mesoporous Mater 60:173-181

33. László K, Tombácz E, Josepovits K (2001) Effect of activation on the surface chemistry of carbons from polymer precursors. Carbon 39: $1217-1228$ 